- 研究报告・

\title{
广东省地方鸡线粒体遗传多样性与母系起源
}

\author{
黄勋和 ${ }^{1,2}$ 余哲琪 ${ }^{1}$ 翁茁先 ${ }^{1,2,3}$ 何丹林 ${ }^{4}$ 易振华 ${ }^{4}$ 李威娜 1,2 \\ 陈洁波 1,2 张细权 ${ }^{4}$ 杜炳旺 ${ }^{5}$ 钟福生 ${ }^{1,2,3^{*}}$ \\ 1 (嘉应学院生命科学学院, 广东梅州 514015) \\ 2 (广东省五华三黄鸡科技创新中心, 广东梅州 514015) \\ 3 (湖南农业大学动物科学技术学院, 长沙 410128) \\ 4 (华南农业大学动物科学学院, 广州 510642) \\ 5 (广东海洋大学农学院, 广东湛江 524088)
}

摘要: 系统评估地方鸡的遗传变异水平并追溯其母系起源, 可为保护利用优质家禽种质资源库提供科学依据。本 研究测定了广东省和邻省共 12 个地方鸡品种的线粒体DNA D-loop序列, 分析品种间的遗传距离与系统关系, 并构 建单倍型系统发生树和中介网络图。360份样品共检测到60个突变位点, 均为转换。定义了 85 种单倍型, 归属于单 倍型类群A、B、C和E, 在12个鸡品种中均有分布, 其中B是优势单倍型类群(187个, 51.94\%), E次之(76个, 21.11\%)。 B02 和C01是优势单倍型(85个, 23.61\%; 48个, 13.33\%), 为12个鸡品种共有; E03位居第三(35个, 9.72\%), 杏花鸡、 黄郎鸡和宁都三黄鸡未见此单倍型。杏花鸡集中分布在单倍型类群B, 惠阳胡须鸡和中山沙栏鸡则主要分布在单 倍型类群E; 怀乡鸡的单倍型数量最多, 中山沙栏鸡的最少。广东地方鸡品种间遗传距离为 $0.012-0.015$, 单倍型多 样性 $0.805 \pm 0.047$ 至 $0.949 \pm 0.026$, 核苷酸多样性 $0.0102 \pm 0.0017$ 至 $0.0138 \pm 0.0009$ 。邻接树和中介网络图将 85 种单 倍型划分为进化枝 $A 、 B 、 C$ 和 $E$, 广东省与邻省地方鸡单倍型的地理分布模式相似。中性检验显示广东地方鸡未 经历明显的群体历史扩张。结果表明广东地方鸡处于较好的保护状态, 遗传多样性水平较高, 品种的形成受到邻 省和北方家鸡的影响，东南亚红原鸡对广东地方鸡也有重要的遗传贡献。

关键词: 广东地方鸡; 线粒体DNA; D-loop; 遗传多样性; 起源

\section{Mitochondrial genetic diversity and maternal origin of Guangdong indigenous chickens}

\author{
Xunhe Huang ${ }^{1,2}$, Zheqi $\mathrm{Yu}^{1}$, Zhuoxian Weng ${ }^{1,2,3}$, Danlin $\mathrm{He}^{4}$, Zhenhua $\mathrm{Yi}^{4}$, Weina $\mathrm{Li}^{1,2}$, Jiebo Chen ${ }^{1,2}$, \\ Xiquan Zhang ${ }^{4}$, Bingwang $\mathrm{Du}^{5}$, Fusheng Zhong ${ }^{1,2,3^{*}}$ \\ 1 School of Life Sciences, Jiaying University, Meizhou, Guangdong 514015 \\ 2 Guangdong Innovation Centre for Science and Technology of Wuhua Yellow Chicken, Meizhou, Guangdong 514015 \\ 3 College of Animal Science and Technology, Hunan Agricultural University, Changsha, Hunan 410128 \\ 4 College of Animal Sciences, South China Agricultural University, Guangzhou, Guangdong 510642 \\ 5 College of Agriculture, Guangdong Ocean University, Zhanjiang, Guangdong 524088
}

\begin{abstract}
The evaluation of the genetic diversity of indigenous chickens and the tracing of their matrilineal origin need to be facilitated to protect and utilize the germplasm bank of quality poultry. Twelve indigenous chicken breeds from Guangdong Province and its adjacent regions were used for mitochondrial DNA (mtDNA) D-loop sequencing, and analyses of genetic distance and genetic relationship between breeds were conducted. We constructed a phylogenetic tree and median-joining network based on haplotypes. Sixty mutation sites were detected in 360 samples, and all of these were found to be in transition. Eighty-five haplotypes, belonging to haplogroups A, B, C, and E, were defined. B was the predominant haplogroup (187, 51.94\%), followed by E (76, 21.11\%). Haplogroups A, B, C, and E were distributed in all the 12 breeds. B02 and C01 were the predominant haplotypes (85, 23.61\%; 48, 13.33\%), which were shared by all twelve
\end{abstract}

收稿日期: 2017-10-08; 接受日期: 2017-12-27

基金项目: 广东省自然科学基金(2014A030307018)、广东省公益研究与能力建设项目(2015A020208020, 2016A030303068)和嘉应学院省市共建重点 建设项目(嘉院(2017)27 号)

* 通讯作者 Author for correspondence. E-mail: zfs@jyu.edu.cn 
breeds; and E03 ranked third (35, 9.72\%), and was absent in the Xinghua, Huanglang and Ningdu yellow chicken. Xinghua chickens occurred mainly in haplogroup B, while Huiyang bearded and Zhongshan shalan chickens were distributed mainly in E. The number of haplotypes of Huaixiang chicken was the largest, while the Zhongshan shalan chicken had the fewest. The genetic distance between Guangdong chicken breeds ranged from 0.012 to 0.015 , with haplotype diversity and nucleotide diversity ranging from $0.805 \pm 0.047$ to $0.949 \pm 0.026$, and from $0.0102 \pm 0.0017$ to $0.0138 \pm 0.0009$, respectively. Eighty-five haplotypes were divided into clades A, B, C, and E in the phylogenetic tree and median-joining network. Similar patterns of geographical distribution of mtDNA haplotypes was found in the chicken from Guangdong Province and its adjacent regions. A neutral test indicated that Guangdong indigenous chickens have not sustained obvious population expansion. Our results suggested that Guangdong chickens have a desirable conservation status, as they carry high levels of genetic diversity, and demographic histories were influenced to some extent, by the gene flow of domestic chickens from adjacent provinces and northern China. The red junglefowls from Southeast Asia have an important genetic contribution to the indigenous chickens of Guangdong Province.

Key words: Guangdong indigenous chicken; mitochondrial DNA; D-loop; genetic diversity; origin

家鸡作为分布最广泛的畜禽品种之一, 为人类 提供了稳定的蛋白质来源, 同时在医学研究、宗教、 娱乐和装饰等方面也有重要用途(Lawler, 2015)。地 方家禽遗传资源是经长期进化而形成的宝贵资源, 是未来家禽品种改良和适应生产条件变化、保持生 产长期持续发展的遗传基础(国家畜禽遗传资源委 员会, 2011)。广东省位于华南地区的中心, 与福建、 广西、湖南及江西接壤, 与海南省隔海相望, 在“无 鸡不成宴” 的地方民俗及地理环境和历史的共同作 用下, 广东省形成了丰富的地方鸡品种资源(篗浩 等, 2004; 张细权等, 2006)。广东省拥有7个优质地 方鸡品种, 是我国家鸡品种数量较多的省份之一, 其中怀乡鸡、惠阳胡须鸡、清远麻鸡、杏花鸡、阳 山鸡和中山沙栏鸡入选《中国畜禽遗传资源志: 家 禽志》(国家畜禽遗传资源委员会, 2011), 五华三黄 鸡也入选了《中国禽类遗传资源》(陈国宏等, 2004)。 近年来, 一些研究涉及广东地方鸡品种的遗传多样 性评估及驯化历史。然而, 由于微卫星标记(Qu et al, 2006; 黄勋和等, 2016a, b; Huang et al, 2016)和DNA 条形码技术(黄勋和等, 2016c)提供群体历史的遗传 信息有限, 或研究品种数量较少(Wu et al, 2014), 广东省地方鸡群体历史还需深入探究。

线粒体DNA (mitochondrial DNA, mtDNA)具有 母系遗传、无重组、突变速率快等特点, 能够反映 近期历史进化事件, 被广泛用于家养动物遗传多样 性评估分析以及追溯起源与驯化历史的研究工作 (Lan et al, 2017; Zhang et al, 2017)。Liu等(2006)从全 球视角分析了家鸡的母系起源, 将家鸡/原鸡mtDNA 世系分为 9 个高度分化的单倍型类群(haplogroup)
(A-I), 其中 7个 (C和H除外)为野生红原鸡和家鸡所 共有。一些单倍型类群表现出明显的系统地理结构, 如 $\mathrm{A}$ 和 $\mathrm{B}$ 主要分布于华南和日本, C主要发现在日本 和中国东南部, $F$ 和 $G$ 则局限分布于中国西南和东 南亚, 表明家鸡在中国南方、东南亚和印度次大陆 得到广泛的传播。针对先前研究样本量小和序列信 息不足等问题, Miao等(2013)扩大了样本量并从中 选取50份代表样本进行 mtDNA全基因组测定, 结 合11条已发表的序列，构建 $\mathrm{mtDN}$ 系统发育树并对 单倍型类群进行了系统界定。他们的研究结果极大 拓展了对家鸡复杂的驯化与扩散历史的认识, 提 示家鸡和红原鸡之间可能存在持续杂交，或是家 鸡的驯化时间较短; 同时首次从单倍型亚类群 (sub-haplogroup)水平揭示了分别发生在南亚、中国 西南及其邻近东南亚地区的局部驯化事件, 为后 续家鸡起源驯化研究提供了新思路。

本文以广东省 7 个地方鸡品种为研究对象, 并 与邻省 5 个地方鸡种相比较, 评估广东地方鸡品种 mtDNA D-loop的遗传多样性水平, 探讨其母系来 源, 为广东省地方鸡品种的科学保护和合理利用提 供参考依据。

\section{材料与方法}

\section{1 实验材料}

实验材料为 7 个广东地方鸡品种以及邻省福 建、广西、海南、湖南、江西各 1 个品种(表 1$)$ 。其 中五华三黄鸡入选《中国禽类遗传资源》(陈国宏等, 2004), 其他11个地方鸡品种入选《中国畜禽遗传资 源志: 家㥐志》(国家畜命遗传资源委员会, 2011)。 
采集地为原产地或保种场。每个品种随机选取30个 个体肱静脉取血，置于 $70 \%$ 乙醇于 $-80^{\circ} \mathrm{C}$ 保存。采用 血液DNA小量提取试剂盒(广州美基生物科技有限 公司)提取基因组DNA, $-20^{\circ} \mathrm{C}$ 保存备用。中国南方、 北方和西南地区以及东南亚、南亚家鸡共3,363条 mtDNA D-loop序列在GenBank (http://www.ncbi.nlm. nih.gov/nuccore)下载。

\subsection{PCR扩增与序列测定}

mtDNA D-loop扩增引物: L16750, 5'-AGGAC TACGGCTTGAAAAGC-3'(Fumihito et al, 1994); H522，5'-ATGTGCCTGACCGAGGAACCAG-3' ( 傅 衍等，2001)。反应体系为 $30 \mu \mathrm{L}$ ，包括 $10 \times \mathrm{PCR}$ Buffer $\left(\right.$ 含 $\mathrm{Mg}^{2+}$ ) $3 \mu \mathrm{L}$, dNTP mixture (2.5 mM) $2.4 \mu \mathrm{L}$, 正、反向引物 $(20 \mu \mathrm{M})$ 各 $0.3 \mu \mathrm{L}$, 模板DNA $1 \mu \mathrm{L}, r T a q$ DNA聚合酶(宝生物工程(大连)有限公司) $(5 \mathrm{U} / \mu \mathrm{L})$ $0.3 \mu \mathrm{L}$ 。 $\mathrm{PCR}$ 扩增条件: $94^{\circ} \mathrm{C}$ 预变性 $4 \mathrm{~min} ; 94^{\circ} \mathrm{C}$ 变性 $30 \mathrm{~s}, 63^{\circ} \mathrm{C}$ 复性 $1 \mathrm{~min}, 72^{\circ} \mathrm{C}$ 延伸 $50 \mathrm{~s}$, 执行 35 个循环; 最后 $72^{\circ} \mathrm{C}$ 延伸7 min。PCR扩增产物用 $1.5 \%$ 琼脂糖凝 胶电泳检测后，由广州艾基生物技术有限公司进行 双向测序。

\section{3 序列分析}

使用软件Bioedit (Hall et al, 1999)校对测序序 列; Clustal_X 1.81 (Thompson et al, 1997)比对序列 后, 以红原鸡mtDNA序列(NC_007235)作为参考序 列，使用DnaSP 6.10 .01 (Rozas et al, 2017)定义单倍 型, 提取变异位点信息(variable sites, V), 计算单倍 型多样性(haplotype diversity, Hd)、核苷酸多样性 (nucleotide diversity, $\pi$ )、核苷酸差异均数(average number of nucleotide differences, $\mathrm{K}$ ), 并进行Tajima’s 中性检验。用MEGA 6.0 (Tamura et al, 2013)分析其碱 基组成, Kimura 2-parameter (K2P)模型计算遗传距 离, 采用邻接法(neighbor-joining, $\mathrm{NJ}$ )构建广东省和 邻省家鸡单倍型的系统发育树。通过NETWORK 5.0.0.1 (Bandelt et al, 1999)构建广东省与邻省地方鸡 线粒体单倍型的中介网络图(median-joining network)。

\section{结果}

\section{1 遗传多样性}

移除引物序列之后, 获得了520 bp mtDNA D-loop序列，其中碱基A、T、G、C的平均含量分别 为 $27.4 \% 、 30.1 \% 、 12.6 \% 、 29.9 \%, \mathrm{~A}+\mathrm{T}$ 和 $\mathrm{G}+\mathrm{C}$ 的平 均含量分别为 $57.5 \%$ 、 $42.5 \%$ 。3 360 份样品共检测到 60 个突变位点，占总分析位点的 $11.54 \%$ 。其中简约 信息位点 33 个，单一突变位点 27 个。突变类型均为 转换, 包括 23 个 $\mathrm{A} \rightarrow \mathrm{G}$ 转换和 37 个 $\mathrm{T} \rightarrow \mathrm{C}$ 转换, 未检 测到插入或缺失。以NC_007235为参考序列，在60 个突变位点中定义了 85 种单倍型，归属于单倍型类 群A、B、C和E (表2)。其中，单倍型类群A、B、C 和 $E$ 在12种鸡品种中均有分布; $B$ 是优势单倍型类群 (187个, 51.94\%), E次之(76个, 21.11\%)。在85种单倍 型中, 有共享单倍型21种; 黄郎鸡、河田鸡和清远 麻鸡的特有单倍型分别为 $10 、 9$ 和 8 种。B 02 和 C01 是优势单倍型(分别为 85 个, $23.61 \%$; 48个, $13.33 \%$ ), 为 12 个鸡品种共有; 单倍型E03位居第三(35个,

表1 本研究的样品信息(每个品种均取30个样本)

Table 1 Sample information of the present study (30 samples for every chicken breed)

\begin{tabular}{lll}
\hline 品种 Breed & 代号 Code & 产地 Origin \\
\hline 怀乡鸡 Huaixiang chicken & HX & 广东省信宜市 Xinyi, Guangdong \\
杏花鸡 Xinghua chicken & XH & 广东省封开县 Fengkai, Guangdong \\
阳山鸡 Yangshan chicken & YS & 广东省阳山县 Yangshan, Guangdong \\
清远麻鸡 Qingyuan spotted chicken & QY & 广东省清远市 Qingyuan, Guangdong \\
惠阳胡须鸡 Huiyang bearded chicken & HY & 广东省惠州市 Huizhou, Guangdong \\
五华三黄鸡 Wuhua yellow chicken & WH & 广东省五华县 Wuhua, Guangdong \\
中山沙栏鸡 Zhongshan shalan chicken & SL & 广东省中山市 Zhongshan, Guangdong \\
广西三黄鸡 Guangxi yellow chicken & GX & 广西省桂平市 Guiping, Guangxi \\
文昌鸡 Wenchang chicken & WC & 海南省文昌市 Wenchang, Hainan \\
河田鸡 Hetian chicken & HT & 福建省长汀县 Changting, Fujian \\
黄郎鸡 Huanglang chicken & HL & 湖南省衡南县 Hengnan, Hunan \\
宁都三黄鸡 Ningdu yellow chicken & ND & 江西省宁都县 Ningdu, Jiangxi \\
\hline
\end{tabular}


表2 12种地方鸡mtDNA D-loop的单倍型及其在品种中的分布。*表示参考序列NC_007235对应的变异位点位置，圆点表示 与参考序列具有相同的碱基。

Table 2 mtDNA D-loop haplotypes and their distribution in the 12 indigenous chicken breeds. Star (*) indicate the corresponding position with the reference sequence NC_007235, Dots (.) within the nucleotide position indicate the same nucleotides as given in reference sequences.

\begin{tabular}{|c|c|c|c|}
\hline $\begin{array}{l}\text { 单倍型 } \\
\text { Haplotype } \\
\end{array}$ & $\begin{array}{l}\text { 变异位点 }{ }^{*} \\
\text { Variable sites }\end{array}$ & $\begin{array}{l}\text { 单倍型的品种分布(频率) } \\
\text { Haplotype distribution in breeds (frequency) }\end{array}$ & $\begin{array}{l}\text { 合计 } \\
\text { Total }\end{array}$ \\
\hline NC_007235 & $\begin{array}{r}1111112222222222222222222222222233333333333333333333334444444 \\
356899011112223334445556788989990011123333445566689991334467 \\
387279102790250792362691413162694603590135274523741690456960 \\
\text { 5 TGTTTTTCATCTACTAAGTTATATAAAAAACTTTCCTACTTAAATTCCTACTGTAGCTAT }\end{array}$ & & \\
\hline A01 & $\ldots$ C. $\ldots$ G. $\ldots$ T. $\ldots$ C. $\ldots$ C. $\ldots \ldots \ldots$. $\ldots \ldots \ldots \ldots \ldots \ldots \ldots$ & $\begin{array}{l}\text { HX2, HY1, QY3, WH4, XH2, YS3, SL2, } \\
\text { GX1, WC1, HL1 }\end{array}$ & 20 \\
\hline A02 & 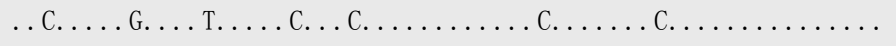 & XH1 & 1 \\
\hline A03 & 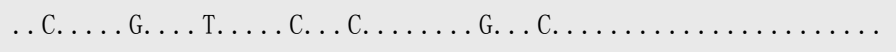 & XH1 & 1 \\
\hline A04 & . C.... G. . T. . G. . C. . C. . . . . . C $\ldots \ldots \ldots \ldots \ldots \ldots \ldots$ & HY1, YS2 & 3 \\
\hline A05 & 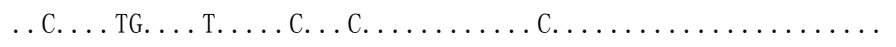 & HX1 & 1 \\
\hline A06 & 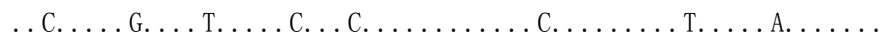 & HY1 & 1 \\
\hline A07 & 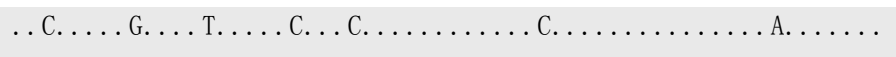 & HX1, HT1, HL2 & 4 \\
\hline A08 & 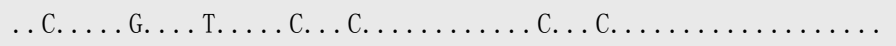 & HY1 & 1 \\
\hline A09 & 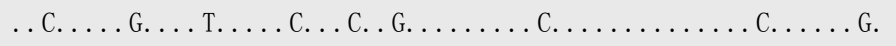 & HL1 & 1 \\
\hline A10 & 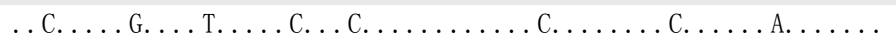 & HL1 & 1 \\
\hline A11 & 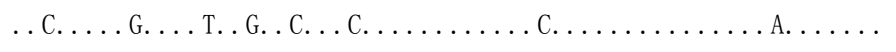 & HT1 & 1 \\
\hline A12 & 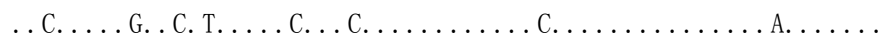 & HT2 & 2 \\
\hline B01 & $\ldots \ldots \ldots \ldots \ldots \ldots \ldots \ldots \ldots$ & XH2, ND1 & 3 \\
\hline B02 & $\ldots \ldots \ldots \ldots \ldots \ldots \ldots+\ldots \ldots$ & $\begin{array}{l}\text { HX6, HY6, QY7, WH5, XH8, YS9, SL5, } \\
\text { HT1, GX20, WC13, HL2, ND3 }\end{array}$ & 85 \\
\hline B03 & .......... Т. & XH2, GX1, WC1, HL1 & 5 \\
\hline B04 & 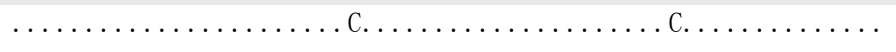 & XH3 & 3 \\
\hline B05 & $\ldots \ldots \ldots \ldots \ldots \ldots \ldots$ GC. $\ldots \ldots \ldots$ C. $\ldots \ldots \ldots$ & XH3 & 3 \\
\hline B06 & $\ldots \ldots \ldots \ldots \ldots \ldots \ldots$ A. С. $\ldots \ldots \ldots \ldots \ldots \ldots$ & XH2 & 2 \\
\hline B07 & 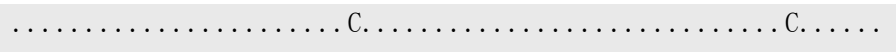 & XH1 & 1 \\
\hline B08 & ................ С. & WH2, YS2, GX1, WC1, HL1 & 7 \\
\hline B09 & 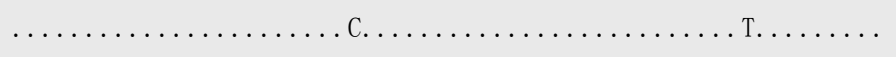 & HX1, WH1, YS1, HT1, ND1 & 5 \\
\hline B10 & 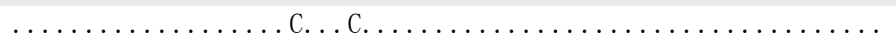 & HX1 & 1 \\
\hline B11 & $\ldots \ldots \ldots \ldots \ldots$ С................ & HX1 & 1 \\
\hline B12 & 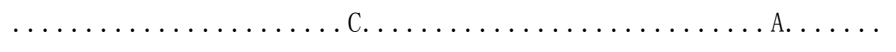 & HX3, WH3, HT6, HL2, ND9 & 23 \\
\hline B13 & $\ldots \ldots \ldots \ldots$ Т. & HX1, ND2 & 3 \\
\hline B14 & $\ldots \ldots \ldots \ldots \ldots$ с. $\ldots$ т. $\ldots \ldots \ldots \ldots \ldots$ А. $\ldots \ldots$ & HX1 & 1 \\
\hline B15 & 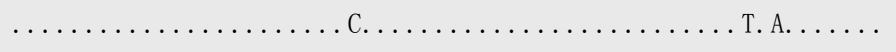 & HX1 & 1 \\
\hline B16 & 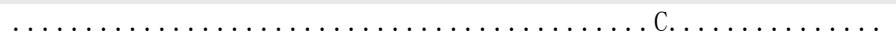 & WH1 & 1 \\
\hline B17 & $\ldots \ldots \ldots \ldots \ldots \ldots \ldots \ldots$ C. $\ldots \ldots$ А. $\ldots \ldots$ & WH1 & 1 \\
\hline B18 & $\ldots \ldots$ С.......... & QY1 & 1 \\
\hline B19 & 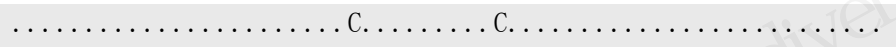 & QY1, WC1 & 2 \\
\hline B20 & $\ldots \ldots \ldots \ldots \ldots$ C. G. . & QY1 & 1 \\
\hline B21 & $\ldots$ С.............. & QY1 & 1 \\
\hline B22 & 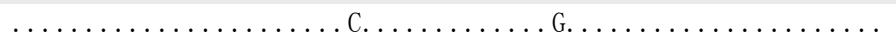 & QY1 & 1 \\
\hline B23 & $\ldots \ldots \ldots \ldots \ldots \ldots$ С...С. $\ldots \ldots \ldots \ldots \ldots$ & SL2 & 2 \\
\hline B24 & 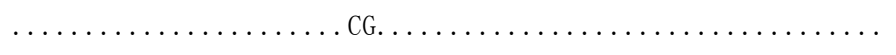 & SL1 & 1 \\
\hline B25 & $\ldots \ldots \ldots \ldots \ldots \ldots \ldots \ldots$ С $\ldots \ldots \ldots \ldots \ldots$ С. $\ldots \ldots \ldots \ldots \ldots \ldots$ & HY1 & 1 \\
\hline
\end{tabular}


表2 (续) Table 2 (continued)

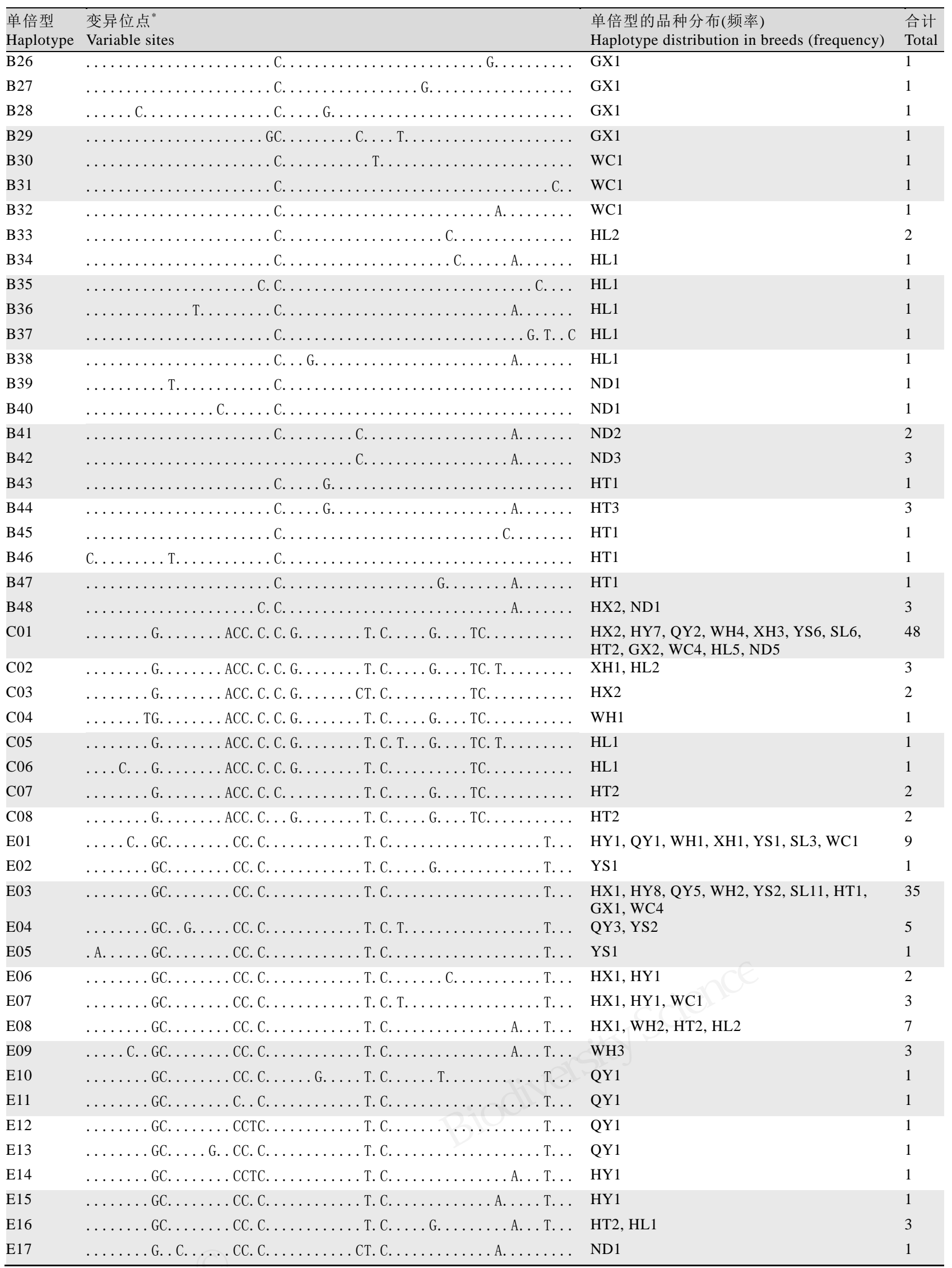


9.72\%), 杏花鸡、黄郎鸡和宁都三黄鸡未见此单 倍型。

7 个广东省地方鸡品种集中分布在单倍型类群 $A 、 B 、 C$ 和E中，对应的频率分别为12.38\% (26/210)、 $42.86 \%(90 / 210) 、 16.19 \% \quad(34 / 210)$ 和 $28.57 \%$ (60/210)。不同品种的单倍型、单倍型类群组成有 所差异, 怀乡鸡的单倍型数量最多, 中山沙栏鸡的 最少; 杏花鸡主要集中分布在单倍型类群 $\mathrm{B}$, 惠阳 胡须鸡和中山沙栏鸡则主要分布在单倍型类群 $\mathrm{E}$ (表2，表3)。
12 个地方鸡品种总体单倍型多样性为 $0.909 \pm$ 0.010 , 核苷酸多样性为 $0.0130 \pm 0.0003$, 平均核苷 酸差异为6.739, 其中黄郎鸡、河田鸡和五华三黄鸡 的核苷酸多样性最高，广西三黄鸡最低(表3)。中性 检测显示，除了广西三黄鸡以外，其他地方鸡的 Tajima's $D$ 值差异均不显著(表3)。12个群体间的净 遗传距离为 $0-0.005$, 其中广西三黄鸡与中山沙栏 鸡和惠阳胡须鸡、宁都三黄鸡与中山沙栏鸡的净遗 传距离最大; 品种间双参数遗传距离介于 $0.008-$ 0.016 之间(表4)。

表3 12个地方鸡品种的线粒体DNA D-loop遗传多样性统计。品种代号同表1。

Table 3 Genetic diversity of mtDNA D-loop in the 12 indigenous chicken breeds. Breed codes are the same with Table 1.

\begin{tabular}{|c|c|c|c|c|c|c|c|}
\hline $\begin{array}{l}\text { 品种 } \\
\text { Breed }\end{array}$ & $\begin{array}{l}\text { 突变位点数 } \\
\text { Variable sites }\end{array}$ & $\begin{array}{l}\text { 单倍型数量 } \\
\text { No. of haplotypes }\end{array}$ & $\begin{array}{l}\text { 单倍型类群(个体数) } \\
\text { Haplogroups } \\
\text { (individuals) }\end{array}$ & $\begin{array}{l}\text { 单倍型多样性 } \\
\text { Haplotype } \\
\text { diversity (SD) }\end{array}$ & $\begin{array}{l}\text { 核苷酸多样性 } \\
\text { Nucleotide } \\
\text { diversity (SD) }\end{array}$ & $\begin{array}{l}\text { 平均核苷酸差异 } \\
\text { Average number } \\
\text { of nucleotide } \\
\text { differences }\end{array}$ & $\begin{array}{l}\text { Tajima's } D \\
\text { 检验 } \\
\text { Tajima's } D \\
\text { test }\end{array}$ \\
\hline HX & 26 & $19(\mathrm{~A}=4, \mathrm{~B}=9, \mathrm{C}=2, \mathrm{E}=4)$ & $\mathrm{A}(5), \mathrm{B}(17), \mathrm{C}(4), \mathrm{E}(4)$ & $0.949(0.026)$ & $0.0123(0.0014)$ & 6.382 & -0.0987 \\
\hline $\mathrm{HY}$ & 25 & $12(A=3, B=2, C=1, E=6)$ & $\mathrm{A}(3), \mathrm{B}(7), \mathrm{C}(7), \mathrm{E}(13)$ & $0.853(0.039)$ & $0.0132(0.0008)$ & 6.837 & 0.2969 \\
\hline QY & 27 & $15(\mathrm{~A}=1, \mathrm{~B}=6, \mathrm{C}=1, \mathrm{E}=7)$ & $\mathrm{A}(3), \mathrm{B}(12), \mathrm{C}(2), \mathrm{E}(13)$ & $0.913(0.032)$ & $0.0127(0.0008)$ & 6.623 & -0.1011 \\
\hline WH & 21 & $13(\mathrm{~A}=1, \mathrm{~B}=6, \mathrm{C}=2, \mathrm{E}=4)$ & $\mathrm{A}(4), \mathrm{B}(13), \mathrm{C}(5), \mathrm{E}(8)$ & $0.929(0.022)$ & $0.0138(0.0009)$ & 7.177 & 1.2395 \\
\hline $\mathrm{XH}$ & 25 & $13(\mathrm{~A}=3, \mathrm{~B}=7, \mathrm{C}=2, \mathrm{E}=1)$ & $A(4), B(21), C(4), E(1)$ & $0.906(0.036)$ & $0.0102(0.0017)$ & 5.285 & -0.6955 \\
\hline YS & 22 & $11(\mathrm{~A}=2, \mathrm{~B}=3, \mathrm{C}=1, \mathrm{E}=5)$ & $A(5), B(12), C(6), E(7)$ & $0.867(0.042)$ & $0.0134(0.0009)$ & 6.989 & 0.9093 \\
\hline SL & 18 & $7(\mathrm{~A}=1, \mathrm{~B}=3, \mathrm{C}=1, \mathrm{E}=2)$ & $\mathrm{A}(2), \mathrm{B}(8), \mathrm{C}(6), \mathrm{E}(14)$ & $0.805(0.047)$ & $0.0120(0.0009)$ & 6.248 & 1.2923 \\
\hline GX & 24 & $10(\mathrm{~A}=1, \mathrm{~B}=7, \mathrm{C}=1, \mathrm{E}=1)$ & A(1), B (26), C(2), E(1) & $0.561(0.109)$ & $0.0055(0.0018)$ & 2.839 & $-1.8847^{*}$ \\
\hline HL & 30 & $20(\mathrm{~A}=4, \mathrm{~B}=10, \mathrm{C}=4, \mathrm{E}=2)$ & $\mathrm{A}(5), \mathrm{B}(13), \mathrm{C}(9), \mathrm{E}(3)$ & $0.963(0.021)$ & $0.0155(0.0009)$ & 8.025 & 0.2160 \\
\hline HT & 25 & $17(\mathrm{~A}=3, \mathrm{~B}=8, \mathrm{C}=3, \mathrm{E}=3)$ & $A(4), B(15), C(6), E(5)$ & $0.945(0.025)$ & $0.0141(0.0011)$ & 7.317 & 0.5680 \\
\hline ND & 18 & $12(\mathrm{~B}=10, \mathrm{C}=1, \mathrm{E}=1)$ & $\mathrm{B}(24), \mathrm{C}(5), \mathrm{E}(1)$ & $0.876(0.041)$ & $0.0097(0.0019)$ & 5.039 & 0.1757 \\
\hline WC & 23 & $12(\mathrm{~A}=1, \mathrm{~B}=7, \mathrm{C}=1, \mathrm{E}=3)$ & $A(1), B(19), C(4), E(6)$ & $0.793(0.067)$ & $0.0108(0.0015)$ & 5.630 & -0.1070 \\
\hline $\begin{array}{l}\text { 合计 } \\
\text { Total }\end{array}$ & 60 & $\begin{array}{l}85(\mathrm{~A}=12, \mathrm{~B}=48, \mathrm{C}=8, \\
\mathrm{E}=17)\end{array}$ & $\begin{array}{l}\mathrm{A}(37), \mathrm{B}(187), \mathrm{C}(60), \\
\mathrm{E}(76)\end{array}$ & $0.909(0.010)$ & $0.0130(0.0003)$ & 6.739 & -0.9237 \\
\hline
\end{tabular}

${ }^{*} P<0.05$

表4 12个鸡品种间的净遗传距离(上三角)和Kimura双参数距离(下三角)。品种代号同表1。

Table 4 Net distances (above diagonal) and K2P distance (below diagonal) among 12 chicken breeds. Breed codes are the same with Table 1.

\begin{tabular}{llllllllllllll}
\hline 品种 breed & XH & YS & HX & WH & QY & SL & HY & GX & WC & HL & ND & HT \\
\hline XH & & 0.001 & 0.000 & 0.001 & 0.002 & 0.003 & 0.003 & 0.000 & 0.000 & 0.001 & 0.001 & 0.001 \\
YS & 0.013 & & 0.000 & 0.000 & 0.000 & 0.000 & 0.000 & 0.002 & 0.000 & 0.000 & 0.002 & 0.000 \\
HX & 0.012 & 0.013 & & 0.000 & 0.001 & 0.002 & 0.002 & 0.001 & 0.000 & 0.000 & 0.000 & 0.000 \\
WH & 0.013 & 0.014 & 0.013 & & 0.000 & 0.000 & 0.000 & 0.002 & 0.000 & 0.000 & 0.001 & 0.000 \\
QY & 0.013 & 0.013 & 0.014 & 0.014 & & 0.000 & 0.000 & 0.003 & 0.000 & 0.001 & 0.003 & 0.001 \\
SL & 0.015 & 0.013 & 0.014 & 0.014 & 0.013 & & 0.000 & 0.005 & 0.002 & 0.001 & 0.005 & 0.002 \\
HY & 0.015 & 0.014 & 0.015 & 0.014 & 0.013 & 0.012 & & 0.005 & 0.002 & 0.001 & 0.004 & 0.002 \\
GX & 0.008 & 0.012 & 0.010 & 0.012 & 0.012 & 0.014 & 0.015 & & 0.001 & 0.002 & 0.001 & 0.002 \\
WC & 0.011 & 0.013 & 0.012 & 0.013 & 0.012 & 0.013 & 0.014 & 0.009 & & 0.001 & 0.001 & 0.001 \\
HL & 0.014 & 0.015 & 0.014 & 0.015 & 0.015 & 0.015 & 0.016 & 0.013 & 0.014 & & 0.001 & 0.000 \\
ND & 0.011 & 0.014 & 0.012 & 0.013 & 0.014 & 0.016 & 0.016 & 0.008 & 0.011 & 0.014 & & 0.001 \\
HT & 0.013 & 0.015 & 0.013 & 0.014 & 0.015 & 0.015 & 0.015 & 0.012 & 0.013 & 0.015 & 0.013 & \\
\hline & & & & & & & & & & &
\end{tabular}


2.2 系统进化

广东省和邻省家鸡单倍型邻接树(图1)显示, 85 种单倍型被划分为进化枝 $A 、 B 、 C$ 和 $E ; A$ 和B进一步
聚为一枝, C和E也聚为一个更大的进化枝(图1)。中介 网络图明显地将单倍型划分为 $A 、 B 、 C$ 和 $E$ 四个类 群(图2)。不同鸡品种在不同单倍型类群的分布频率

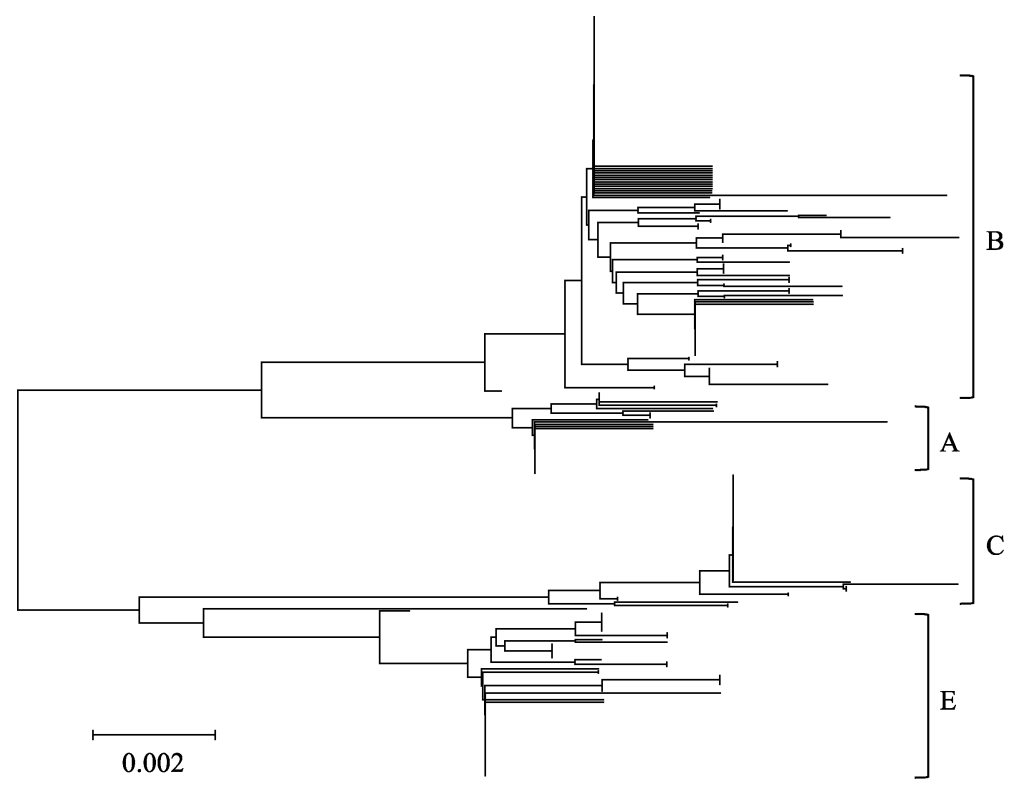

图1 基于85种广东省和邻省家鸡线粒体DNA D-loop单倍型构建的邻接树

Fig. 1 Neighbor-joining tree of 85 mtDNA D-loop haplotypes from Guangdong and its adjacent provinces indigenous chicken breeds

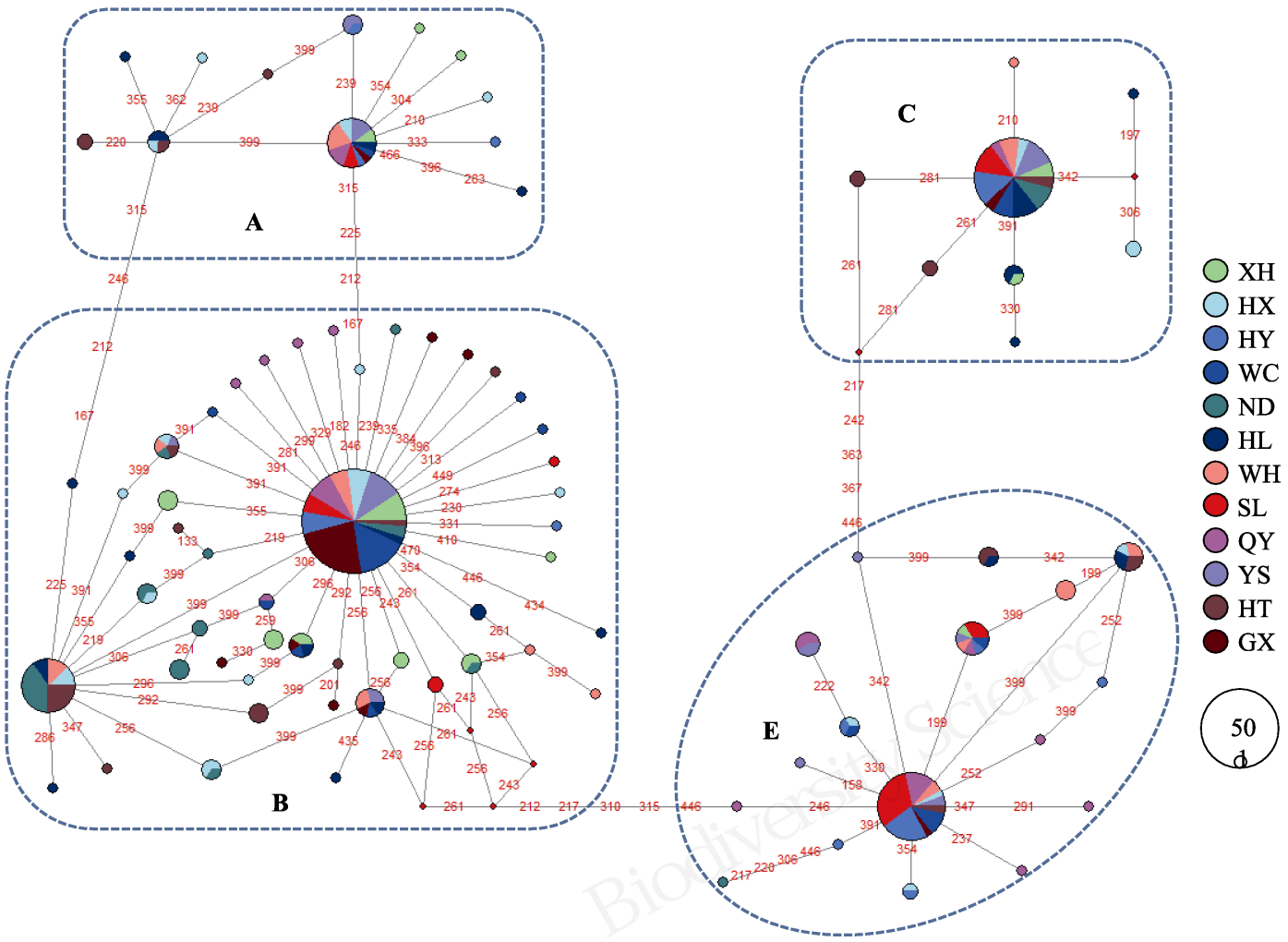

图2 广东省和邻省12种地方鸡线粒体DNA D-loop单倍型的中介网络图。连接点数字表示核苷酸转换的位置; 圆的大小对应 单倍型频率; 不同鸡品种用不同颜色标注。品种代号同表1。

Fig. 2 Median-joining network of mtDNA D-loop haplotypes of 12 indigenous chicken breeds from Guangdong and its adjacent provinces. The links are labeled by the nucleotide positions to designate transitions. Cycle size is roughly proportional to the haplotype frequency. The breeds are indicated by different colors. Breed codes are the same with Table 1. 
不一致, 其中 B是优势单倍型类群, 单倍型数量也 最多。7个广东地方鸡品种在单倍型类群A、B、C 和E均有分布。

\section{3 进化枝地理格局}

本实验共统计了 3,723只家鸡mtDNA D-loop的 分布情况，进化枝 A、B、C和E在所有地区都有分布， 其中 B为优势单倍型类群，约占总个体数的 $29.95 \%$, $\mathrm{A}$ 次之, 约占总数的 $22.70 \%$, E位居第三, 约占总数 的 $22.08 \%$ (表5)。单倍型类群C在中国南方、中国北 方分布广泛, 而在中国西南、东南亚和南亚分布较 少。家鸡的线粒体单倍型分布具有一定的地理特性, 部分地区的单倍型类群组成相似(如中国北方和广 东省, 东南亚和南亚), 而中国西南、东南亚、南亚 家鸡明显拥有更丰富的遗传变异水平。

\section{3 讨论}

本文应用mtDNA D-loop分子标记系统研究了 7 种广东省地方鸡以及 5 种邻省地方鸡的遗传多样性 并探讨其起源。与其他地区的地方鸡相比, 如广西 (Liao et al, 2016)、江西(Gao et al, 2017)和华东(贾晓 旭等, 2017), 广东地方鸡的遗传多样性均处于较高 水平, 这与微卫星DNA的研究结论一致(Huang et al, 2016; 黄勋和等, 2016a)。广东省较早开展了优质地 方家禽品种资源现状的调查工作, 并挖掘出一批特
有性状的品种(篗浩等，2004)，7个地方鸡品种现均 已建立了保种场，并且制定了科学的保护策略，地 方鸡品种处于较好的保护状态。

广东省地方鸡的遗传组成与地理分布有关。B 是广东地方鸡的优势单倍型类群，约占总数的 42.86\% (90/210), 与中国南方其他地方鸡(394/863, 45.65\%)和东南亚家鸡(289/621，46.54\%)单倍型组 成相似; 同时, 广东地方鸡与邻省地方鸡的遗传距 离较小, 说明广东地方鸡在品种形成的过程中受到 了毗邻省份家鸡的影响。此外, 广东省有广府、客 家和潮汕三大民系，地方鸡的遗传组成与民系的分 布呈一定的相关性。杏花鸡的原产地封开县是粤语 的发源地, 而周边的清远清城区(清远麻鸡)、信 县 (怀乡鸡)、阳山县(阳山鸡)、中山市(中山沙栏鸡)则 是广府、客家的混居地，这些鸡品种的核基因遗传 组成相似(Huang et al, 2016)。惠阳县、紫金县(惠阳 胡须鸡) 和五华县(五华三黄鸡)则是客家的主要分 布地, 这些鸡品种的核基因遗传组成相似(Huang et al, 2016)。

人类活动对家养动物的地理格局形成具有重 要的作用(Langford et al, 2013)。自古以来，广东省 原住居民与外地居民交往密切，尤以与近邻的广 西、湖南、江西，以及福建等东南沿海各地的关系 更为密切。广东省是全国人口迁移与流动最多的省

表5 家鸡主要进化枝的地理分布。 $\mathbf{a}$ 单倍型数量及该地区的独享型单倍型(括号数值); $\mathbf{b}$ 不包括广东省家鸡的数量。

Table 5 Geographical distribution of the major clades in domestic chickens. a, Number of haplotypes and unique haplotypes (in parentheses); b, Excluding those from Guangdong Province.

\begin{tabular}{|c|c|c|c|c|c|c|c|c|c|c|c|}
\hline \multirow{2}{*}{$\begin{array}{l}\text { 地区 } \\
\text { Region }\end{array}$} & \multirow{2}{*}{$\begin{array}{l}\text { 个体数 } \\
\text { Individuals }\end{array}$} & \multicolumn{10}{|c|}{ 单倍型a/个体数 Haplotypes ${ }^{\mathrm{a}} /$ individuals } \\
\hline & & A & B & $\mathrm{C}$ & $\mathrm{D}$ & $\mathrm{E}$ & $\mathrm{F}$ & G & $\mathrm{H}$ & I & $\mathrm{Z}$ \\
\hline $\begin{array}{l}\text { 广东省 } \\
\text { Guangdong }\end{array}$ & 210 & $8(4) / 26$ & $26(13) / 90$ & $5(2) / 34$ & & $15(5) / 60$ & & & & & \\
\hline $\begin{array}{l}\text { 中国北方 } \\
\text { northern } \\
\text { China }\end{array}$ & 273 & $25(12) / 111$ & $11(6) / 66$ & $11(2) / 59$ & $2 / 2$ & $8 / 35$ & & & & & \\
\hline $\begin{array}{l}\text { 中国南方 }{ }^{b} \\
\text { southern } \\
\text { China }\end{array}$ & 863 & $28(17) / 182$ & $67(45) / 394$ & $22(12) / 131$ & $5(3) / 13$ & $17(3) / 137$ & $1 / 1$ & $2 / 4$ & & & $1(1) / 1$ \\
\hline $\begin{array}{l}\text { 中国西南 } \\
\text { southwest } \\
\text { China }\end{array}$ & 1,153 & $36(19) / 366$ & $22(12) / 260$ & $6(2) / 29$ & & 9/98 & $22(16) / 152$ & $40(31) / 237$ & $3(3) / 11$ & & \\
\hline $\begin{array}{l}\text { 东南亚 } \\
\text { Southeast } \\
\text { Asia }\end{array}$ & 621 & $38(29) / 146$ & $53(41) / 289$ & $5(2) / 19$ & $45(41) / 67$ & $15(9) / 42$ & $12(9) / 38$ & $4(1) / 11$ & $2(2) / 2$ & $3(3) / 7$ & \\
\hline $\begin{array}{l}\text { 南亚 } \\
\text { South Asia }\end{array}$ & 603 & $3(1) / 14$ & $4(1) / 16$ & $19(16) / 31$ & $17(10) / 56$ & $102(79) / 450$ & $3(1) / 12$ & $11(9) / 21$ & & $1(1) / 3$ & \\
\hline 合计 Total & 3,723 & & & & & & & & & & \\
\hline
\end{tabular}


份之一，历史上发生了 4 次北方移民入粤的高潮(广 东省地方史志编纂委员会, 2004)。北方移民入粤过 程中所携带的家鸡与广东省本土家鸡杂交, 形成了 当今广东地方鸡丰富的品种资源。中性检验显示广 东省地方鸡群体没有经历明显的历史扩张, 这可能 与群体交流幅度较小或群体交流历史较近有关。然 而, 由于北方家鸡的遗传起源问题存在较大争议, 还需进一步探讨其对广东家鸡遗传的影响(Xiang et al, 2014; Peng et al, 2015; Peters et al, 2015; Huang et al, 2018)。

另外值得关注的是, 除了中国西南地区, 单倍 型亚类群 $\mathrm{C} 1$ 在东亚家鸡中分布普遍, 而在东南亚和 南亚家鸡中较少分布。现代红原鸡主要分布在中国 西南、广西以及东南亚和南亚地区, 但只有东南亚 和南亚红原鸡存在较为古老的单倍型亚类群 C*(Miao et al, 2013; Huang et al, 2018)。鉴于我国东 南沿海与东南亚地区的经贸往来和人文交流历史, 东南亚家鸡/红原鸡可能对广东省地方鸡的形成有 较大的遗传贡献。

综上，线粒体DNA D-loop研究表明广东地方 鸡的遗传多样性均处于较高水平, 其群体历史受毗 邻省份家鸡和北方移民入粤历史事件以及东南亚 等红原鸡的影响, 从而形成了当今广东省丰富的地 方鸡品种资源。

\section{参考文献}

Bandelt HJ, Forster P, Rohl A (1999) Median-joining networks for inferring intraspecific phylogenies. Molecular Biology and Evolution, 16, 37-48.

Chen GH, Wang KH, Wang JY, Ding C, Yang N (2004) Poultry Genetic Resources in China. Shanghai Scientific and Technical Publishers, Shanghai. (in Chinese) [陈国宏, 王克 华，王金玉，丁铲，杨宁 (2004) 中国禽类遗传资源.上 海科学技术出版社, 上海.]

China National Commission of Animal Genetic Resources (2011) Animal Genetic Resources in China: Poultry. China Agriculture Press, Beijing. (in Chinese) [国家畜禽遗传资 源委员会 (2011) 中国畜禽遗传资源志：家禽志. 中国 农业出版社, 北京.]

Editorial Committee of Local Historiography of Guangdong (2004) Guangdong Provincial Local-Records Compilation: Executive Summary. Guangdong People Press, Guangzhou. (in Chinese) [广东省地方史志编纂委员会 (2004) 广东省 志・总述. 广东人民出版社，广州.]

Fu Y, Niu D, Luo J, Ruan H, He GQ, Zhang YP (2001) Studies of the origin of Chinese domestic fowls. Acta Genetica
Sinica, 28, 411-417. (in Chinese) [傅衍, 牛冬, 罗静, 阮 晖, 何国庆, 张亚平 (2001) 中国家鸡的起源探讨. 遗传 学报, 28, 411-417.]

Fumihito A, Miyake T, Sumi S, Takada M, Ohno S, Kondo N (1994) One subspecies of the red jungle fowl (Gallus gallus gallus) suffices as the matriarchic ancestor of all domestic breeds. Proceedings of the National Academy of Sciences, USA, 91, 12505-12509.

Gao YS, Jia XX, Tang XJ, Fan YF, Lu JX, Huang SH, Tang MJ (2017) The genetic diversity of chicken breeds from Jiangxi, assessed with $\mathrm{BCDO} 2$ and the complete mitochondrial DNA D-loop region. PLoS ONE, 12, e0173192.

Hall TA (1999) Bioedit: A user-friendly biological sequence alignment editor and analysis program for Windows 95/98/NT. Nucleic Acids Symposium Series, 41, 95-98.

Huang XH, Chen JB, He DL, Zhang XQ, Zhong FS (2016c) DNA barcoding of indigenous chickens in China: A reevaluation. Scientia Agricultura Sinica, 49, 2622-2633. (in Chinese with English abstract) [黄勋和, 陈洁波, 何丹林, 张 细权, 钟福生 (2016c) DNA条形码技术鉴定地方鸡品种 的重新评估. 中国农业科学, 49, 2622-2633.]

Huang XH, Li LZ, Zhang JF, He DL, Zhang XQ, Chen JB, Li WN, Du BW, Zhong FS (2016a) Evaluation of diversity and evolution of the microsatellite LEI0258 in chicken MHC-B region from South China. Acta Veterinaria et Zootechnica Sinica, 47, 2175-2183. (in Chinese with English abstract) [黄勋和, 李丽芝, 张金枫, 何丹林, 张细权, 陈洁波, 李 威娜，杜炳旺，钟福生 (2016a) 华南家鸡MHC-B区域复 合微卫星位点LEI0258的遗传多样性与进化研究. 畜牧兽 医学报, 47, 2175-2183.]

Huang XH, Wu YJ, Miao YW, Peng MS, Chen X, He DL, Suwannapoom C, Du BW, Li XY, Weng ZX, Jin SH, Song JJ, Wang MS, Chen JB, Li WN, Otecko NO, Geng ZY, Qu $\mathrm{XY}$, Wu YP, Yang XR, Jin JQ, Han JL, Zhong FS, Zhang XQ, Zhang YP (2018) Was chicken domesticated in northern China? New evidence from mitochondrial genomes. Science Bulletin, DOI: 10.1016/j.scib.2017.12.004.

Huang XH, Zhang JF, He DL, Zhang XQ, Zhong FS, Li WN, Zheng QM, Chen JB, Du BW (2016) Genetic diversity and population structure of indigenous chicken breeds in South China. Frontiers of Agricultural Science and Engineering, 3, 97-101.

Huang XH, Zhang JF, Tan KF, Li LZ, Li WN, Zhong FS (2016b) Diversity and evolution of the highly tandem repeat LEI0258 with in MHC-B region in Wuhua three-yellow chicken. Guangdong Agricultural Sciences, 43, 163-168. (in Chinese with English abstract) [黄勋和, 张金枫, 谭坤凤, 李丽芝, 李威娜, 钟福生 (2016b) 五华三黄鸡MHC-B区 域复合微卫星位点LEI0258遗传多样性与进化研究. 广东 农业科学, 43, 163-168.]

Jia XX, Tang XJ, Fan YF, Lu JX, Huang SH, Ge QL, Gao YS, Han W (2017) Genetic diversity of local chicken breeds in East China based on mitochondrial DNA D-loop region. 
Biodiversity Science, 25, 540-548. (in Chinese with English abstract) [贾晓旭, 唐修君, 樊艳凤, 陆俊贤, 黄胜海, 葛 庆联, 高玉时, 韩威 (2017) 华东地区地方鸡品种mtDNA 控制区遗传多样性. 生物多样性, 25, 540-548.]

Lan D, Hu YD, Zhu Q, Liu Y (2017) Mitochondrial DNA study in domestic chicken. Mitochondrial DNA Part A: DNA Mapping, Sequencing, and Analysis, 28, 25-29.

Langford SM, Kraitsek S, Baskerville B, Ho SYW, Gongora J (2013) Australian and Pacific contributions to the genetic diversity of Norfolk Island feral chickens. BMC Genetics, $14,91$.

Lawler A (2015) Why Did the Chicken Cross the World? G Duckworth, New York.

Liao YY, Mo GD, Sun JL, Wei FY, Liao DJ (2016) Genetic diversity of Guangxi chicken breeds assessed with microsatellites and the mitochondrial DNA D-loop region. Molecular Biology Reports, 43, 415-425.

Liu YP, Wu GS, Yao YG, Miao YW, Luikart G, Baig M, Beja-Pereira A, Ding ZL, Palanichamy MG, Zhang YP (2006) Multiple maternal origins of chickens: Out of the Asian jungles. Molecular Phylogenetics and Evolution, 38, 12-19.

Miao YW, Peng MS, Wu GS, Ouyang YN, Yang ZY, Yu N, Liang JP, Pianchou G, Beja-Pereira A, Mitra B, Palanichamy MG, Baig M, Chaudhuri TK, Shen YY, Kong QP, Murphy RW, Yao YG, Zhang YP (2013) Chicken domestication: An updated perspective based on mitochondrial genomes. Heredity, 110, 277-282.

Peng MS, Shi NN, Yao YG, Zhang YP (2015) Caveats about interpretation of ancient chicken mtDNAs from northern China. Proceedings of the National Academy of Sciences, USA, 112, E1970-E1971.

Peters J, Lebrasseur O, Best J, Miller H, Fothergill T, Dobney K, Thomas RM, Maltby M, Sykes N, Hanotte O, O’Connor T, Collins MJ, Larson G (2015) Questioning new answers regarding Holocene chicken domestication in China. Proceedings of the National Academy of Sciences, USA, 112, E2416.

Qu H, Shu DM, Yang CF (2004) The actuality and development proposal in Guangdong quality chicken germplasm resources. Guangdong Agricultural Sciences, 31(6), 4-7. (in Chinese) [ [翟浩, 舒鼎铭, 杨纯芬 (2004) 广东优质鸡种质 资源的现状及发展建议. 广东农业科学, 31(6), 4-7.]

Qu LJ, Li XY, Xu GF, Chen KW, Yang HJ, Zhang LC, Wu GQ, Hou ZC, Xu GY, Yang N (2006) Evaluation of genetic diversity in Chinese indigenous chicken breeds using microsatellite markers. Science in China Series C: Life Science, 49, 332-341.

Rozas J, Ferrer-Mata A, Sánchez-DelBarrio JC, Guirao-Rico S, Librado P, Ramos-Onsins SE, Sánchez-Gracia A (2017) DnaSP 6: DNA sequence polymorphism analysis of large datasets. Molecular Biology Evolution, 34, 3299-3302.

Tamura K, Stecher G, Peterson D, Filipski A, Kumar S (2013) MEGA6: Molecular Evolutionary Genetics Analysis Version 6.0. Molecular Biology and Evolution, 30, 2725-2729.

Thompson JD, Gibson TJ, Plewniak F, Jeanmougin F, Higgins DG (1997) The Clustal_X Windows interface: Flexible strategies for multiple sequence alignment aided by quality analysis tools. Nucleic Acids Research, 25, 4876-4882.

Wu YP, Huo JH, Xie JF, Liu LX, Wei QP, Xie MG, Kang ZF, Ji HY, Ma YH (2014) Phylogeography and origin of Chinese domestic chicken. Mitochondrial DNA, 25, 126-130.

Xiang H, Gao JQ, Yu BQ, Zhou H, Cai DW, Zhang YW, Chen XY, Wang X, Michael H, Zhao XB (2014) Early Holocene chicken domestication in northern China. Proceedings of the National Academy of Sciences, USA, 111, 11564-11569.

Zhang L, Zhang P, Li QQ, Gaur U, Liu YP, Zhu Q, Zhao XL, Wang Y, Yin HD, Hu YD, Liu AP, Li DY (2017) Genetic evidence from mitochondrial DNA corroborates the origin of Tibetan chickens. PLoS ONE, 12, e0172945.

Zhang XQ, Liang SD, Zhang DX (2006) Review on new breed selection of quality chicken in Guangdong Province. China Poultry, 28(1), 9-11. (in Chinese) [张细权, 梁少东, 张德 祥 (2006) 广东优质鸡新品种选育回顾. 中国家禽, 28(1), 9-11.] 